27 Levine M, Walter S, Lee H, Haines T, Holbrook A, Moyer V. Users' guides to the medical literature. IV. How to use an article about harm. $\mathcal{f} A M A$ 1994;271:1615-9.

28 Laupacis A, Welss G, Richardson WS, Tugwell P. Users' guides to the medical literature. V. How to use an article about prognosis. $\mathscr{f} A M A$ cal literature.

29 Oxman AD, Cook DJ, Guyatt G. Users' guides to the medical literature. VI. How to use an overview. $\mathscr{F} A M A$ 1994;272:1367-71.

30 Husby S, Agertoft L, Mortensen S, Pedersen S. Treatment of croup with nebulised steroid (budesonide): a double blind, placebo controlled study. Arch Dis Child 1992;68:352-5.

31 Geelhoed GC, MacDonald WBG. Oral and inhaled steroids in croup: a randomised, placebo controlled trial. Pediatr Pulmonol 1995;20:355-61.

32 Haines A, Jones R. Implementing findings of research. $B M \mathcal{F}$ 1994;308:1488-92

33 Kairys SW, Marsh Olmstead E, O'Connor GT. Steroid treatment of laryngotracheitis: a meta-analysis of the evidence from randomized trials. Pediatrics 1989;83:683-93.

34 Waring GO. Evaluating new refractive surgical procedures: free market madness versus regulatory rigor mortis. $\mathcal{f}$ Refract Surg 1995;11:335-9.

35 Dawes RM, Faust D, Meehl PE. Clinical versus actuarial judgement. Science 1989;243:1668-74.
36 McKibbon KA, Walker-Dilks CJ. Beyond ACP Journal Club: how to harness MEDLINE for therapy problems. ACP fournal Club 1994;121: A10-2.

37 McKibbon KA, Walker-Dilks CJ. Beyond ACP Journal Club: how to harness MEDLINE for diagnostic problems. ACP fournal Club 1994;121: A10-2.

38 McKibbon KA, Walker-Dilks CJ, Haynes RB. Beyond ACP Journal Club: how to harness MEDLNNE for etiology problems. ACP fournal Club 1994; 121:A10-2.

39 McKibbon KA, Walker-Dilks CJ, Haynes RB, Wilczynski N. Beyond ACP Journal Club: how to harness MEDLNNE for prognosis problems. $A C P$ fournal Club 1994;123:A12-4.

40 Sackett DL Haynes RB. On the need for evidence-based medicine. Evidence-Based Medicine 1995;1:5-6.

41 Bennett RJ, Sackett DL, Haynes RB, Neufeld VR. A controlled trial of teaching critical appraisal of the clinical literature to medical students. FAMA 1987;257:2451-4.

42 Shin JH, Flaynes RB, Johnston ME. Effect of problem-based, self-directed undergraduate education on life-long learning. Can Med Assoc F 1993;148: 969-76.

\title{
Integrated management of childhood infections and malnutrition: a global initiative
}

\section{Global childhood mortality}

Twelve million children die each year before they reach their fifth birthday. The majority $(70 \%)$ of these deaths are due to diarrhoea, pneumonia, measles, malaria, or malnutrition - and often to a combination of these conditions. Moreover, these conditions typically account for three out of four sick children seeking care at a health facility. ${ }^{1}$

Acute respiratory infections (ARI) are the leading cause of mortality in children worldwide, causing one third of all child deaths in 1993 (approximately four million). ${ }^{2}$ Deaths from ARI are mainly due to bacterial pneumonia. ${ }^{2} 3$ Some three million diarrhoeal disease episodes in young children resulted in death in 1993, accounting for $25 \%$ of child deaths. Globally, $50 \%$ of these deaths were due to acute watery diarrhoea, $35 \%$ to persistent diarrhoea, and $15 \%$ to dysentery. Measles and malaria are estimated to be associated with $10 \%$ and $8 \%$ of childhood deaths respectively. The latest World Health Organisation (WHO) estimates state that malnutrition is associated as an underlying cause with $54 \%$ of all childhood deaths, an upward revisions from the earlier estimate of $29 \%{ }^{1}$

Low birth weight, suboptimal breast feeding practices, malnutrition, and maternal behaviour influencing child care are important risk factors associated with increased incidence and severity of these diseases. The most important environmental risk factors are indoor air pollution for pneumonia and inadequate water supply and sanitation for diarrhoeal diseases. HIV infection is an additional risk factor of growing importance. ${ }^{45}$

\section{Need for an integrated approach to the management of sick children}

Almost all developing countries have reported reductions in child mortality in the last 10 years. The United Nations estimates that 13.3 million children under 5 years of age died in the developing world in 1985, and 12.2 million died in $1993 .^{6}$ This represents a decrease from 117 deaths per 1000 live births in 1985 to 97 in 1993. Much has been learned from disease specific control programmes such as those tackling diarrhoeal disease and ARI in the past 15 years. ${ }^{78}$ However experience in developing countries with high child mortality has shown that children presenting with severe illness often have multiple disorders and dem- onstrates the need for a more comprehensive approach to the assessment and management of sick children that ensures prompt recognition of septicaemia, anaemia, malnutrition, and malaria as well as dehydration, dysentery, persistent diarrhoea, and pneumonia. The challenge is now to combine these successful approaches to ARI and diarrhoeal disease case management and extend them to include the clinical management of malaria, measles, meningitis, and malnutrition. The WHO and the Unicef have responded to this challenge and developed an approach based on the integrated management of the sick child. These efforts involve some 12 programmes within WHO and are coordinated by WHO's new Division of Child Health and Development.

\section{Developing integrated case management guidelines} Integrated guidelines for management of the sick child have been developed through a process of review of existing disease specific guidelines, systematic literature review, clinical and health systems research, and field testing. The guidelines promote an approach to clinical management that is appropriate for first level outpatient facilities such as health centres in developing countries. Diagnosis is not dependent on laboratory tests but instead is based solely on valid yet simple clinical signs which health workers from various backgrounds can be trained to recognise accurately. Experience in a number of developing countries has shown that this approach results in health workers making clinical decisions about the management of sick children that accord closely with the independent assessments of experienced paediatricians (WHO, results of Arusha field test, 1995; unpublished).$^{9-11}$ This approach combines several child health interventions. There is evidence of their effectiveness in reducing mortality from community based intervention trials (for example case management of $A R I$, vitamin $A$ administration, and measles immunisation), clinical trials (for example vitamin A treatment in measles), or from observations of decreased case fatality rates after the implementation of standardised guidelines (for example treatment of severe malaria and diarrhoeal disease). ${ }^{12-15}$

The case management guidelines that have been developed are targeted at health workers in busy health centres and outpatient departments of small hospitals. In many circumstances these will be medical assistants, para- 
medical workers, or senior nurses; in other situations, junior doctors. They are designed to give clear practical guidance to diagnosis and treatment of the most important common childhood illnesses. The guidelines describe the following steps. The health worker first assesses the child by asking questions, examining the child, and checking the immunisation status. Then the health worker classifies the child's illnesses, using a colour coded triage system. Each illness is classified according to whether it requires urgent referral, specific medical treatment and advice, or simple advice on home management. After this classification, specific treatments are identified. If the child is to be referred urgently, the health worker gives only essential treatment before the child is transferred. Practical treatment instructions are followed, including how to teach the mother to administer oral drugs, to increase fluid intake during diarrhoea, and to treat local infections at home. The mother is advised on how to recognise the signs which indicate that the child should immediately be brought to the clinic and is given the dates for routine follow up. Feeding is assessed and counselling on feeding problems provided. Follow up instructions for the various conditions are given when the child returns to the clinic.

\section{A training course for first level facility health workers}

An 11 day course has been developed that combines classroom work and hands-on clinical practice built around the integrated case management guidelines. The seven training modules incorporate photo and video exercises, individual feedback on exercises, group discussions, drills, and role plays. The mornings are spent in the clinic or hospital with the sick children, the course providing substantial clinical experience in assessment, classification, treatment, and counselling over 10 clinical sessions. Each participant assesses 30-40 sick children. The substantial clinical experience gained in the course gives the participants confidence in using this approach after training. Communication skills are emphasised in the course and are taught from the first day in each module and during clinical practice, as well as in role plays in the classroom. ${ }^{16}$

\section{CONDITIONS COVERED BY THE COURSE}

At the start of the assessment process all the children are checked for general danger signs that are not disease specific, for example, a child who is lethargic or unconscious, or is unable to drink or breast feed, or vomits everything, or has had convulsions during the illness. These signs may indicate a severe illness requiring urgent referral.

In the case of children aged between 2 months and 5 years, the health worker then asks about four main presenting symptoms: cough or difficult breathing, diarrhoea, fever, and ear problems.

The child presenting with cough or difficult breathing is assessed by the rate of breathing (per minute), looking for chest indrawing and listening for stridor. Chest indrawing, stridor when the child is calm, or one of the general danger signs indicates severe pneumonia or a very severe disease that requires referral. Children with fast breathing alone are classified as having pneumonia. ${ }^{17-21}$ The absence of these signs indicates a simple cough or cold. Children who have been coughing for more than 30 days are referred for further investigation of tuberculosis and other conditions. In countries in which asthma is a significant child health problem, this approach can be adapted to give appropriate management to children with asthma who present with recurrent wheeze. ${ }^{22} \mathrm{~A}$ history and simple examination can lead to diagnosis of mastoiditis and acute and chronic ear infections.

Health workers are taught how to manage acute watery diarrhoea (including cholera), dysentery, and persistent diarrhoea of 14 days or more. The assessment and classification of dehydration draws on years of clinical experience with the WHO diarrhoea case management chart. Rehydration therapy is provided to treat clinically apparent dehydration or to prevent it from developing. Dysentery is treated with an oral antibiotic effective against shigella. Careful nutritional management is provided for persistent diarrhoea, and any extraintestinal infections that may be contributing to the problem are treated.

Children with fever are evaluated for the presence of the most common potentially fatal febrile illnesses. A child with fever and a stiff neck or a general danger sign (see above) may have severe malaria, meningitis, or some other very severe febrile disease. Such children are referred urgently to hospital after treatment with an antibiotic and, in malarious areas, quinine. In an area or season with a high falciparum malaria risk, all children with fever or a history of fever are treated with the oral antimalarial that is recommended for first line treatment of malaria in that country. If the malaria risk is low, the child is given an antimalarial only if another cause for the fever is not apparent. Any child with a fever every day for more than seven days is referred for investigation of typhoid and other conditions. Fever is also the starting point for a diagnosis of measles. The measles case fatality rate can be reduced by good management of the common complications and use of vitamin A. ${ }^{131423}$

All children are assessed for malnutrition and anaemia. Visible severe wasting (marasmus) and oedema of both feet (kwashiorkor) identify children with severe malnutrition who need urgent referral to hospital. A very low weight for age identifies a group of malnourished children whose weight gain should be monitored in a follow up visit and whose feeding needs careful assessment so that any problems can be remedied. Severe pallor is present in a high proportion of children with severe anaemia who require referral to hospital for transfusion. ${ }^{24}$ Children with some palmar pallor are treated with oral iron for two months. ${ }^{25}$

A similar process-assess, classify, identify treatment, treat, and counsel-is taught for the management of the sick young infant (age 1 week up to 2 months).

PREVENTIVE INTERVENTIONS COVERED IN THE COURSE The course includes guidelines for the prevention of disease through the promotion of breast feeding and improved immunisation coverage by ensuring the immunisation of sick children. Age specific feeding recommendations that are acceptable to mothers and common, modifiable feeding problems are identified before the course in each country and the materials adapted to reflect this. ${ }^{26}$ Health workers are taught to compare current feeding practices and to provide focused counselling if a problem is found. In countries where vitamin A deficiency is a problem, health service visits can be used as an opportunity to provide periodic vitamin $A$ supplementation.

\section{Future plans}

The case management training course described above is one component of an integrated approach to the management of childhood infection and malnutrition. Other materials for training and support of health workers that are currently being developed include: a training course for health workers in small hospitals (including guidelines on inpatient care); medical school curricular materials; work- 
shop materials for the management of drug supplies at health facilities; guidelines for monitoring and skill reinforcement by periodic visits to facilities where health workers have completed the course; and a guide to interventions to improve household management of childhood illness, including timely care seeking.

\section{Research issues}

In 1993 and 1994 a series of consultations were organised to obtain expert advice on various topics, to review research findings and to define research priorities. The Divison of Child Health and Development and Division of Tropical Disease Research of WHO are supporting an active research programme focused on these priorities. Most paediatric research in the past has been concentrated on biomedical questions, however there is also a need for behavioural research, for example to identify reasons why mothers do not seek health care for sick children. ${ }^{27}$

\section{Potential impact and cost effectiveness}

According to the World Bank's report for 1993, management of the common childhood infections and malnutrition is the intervention that is likely to have the greatest impact in reducing the global burden of disease. This approach alone is estimated to have the potential to be able to prevent $14 \%$ of that burden in low income countries and is among the most cost effective health interventions in both low income and middle income countries. ${ }^{6}$

\section{Role of paediatricians}

It is important that all paediatricians who work in developing countries or in academic departments in industrialised countries with teaching or research interests in these areas, are fully informed about this global initiative. The clinical guidelines contained in these training materials have been developed through a systematic process of reviewing the most recent research data and gathering expert opinion. This initiative should have an important impact on the quality of clinical paediatric management. It is important to note that these guidelines are, in many areas, quite different to guidelines currently found in standard paediatric textbooks from industrialised countries, which are often slow to incorporate recent advances in the management of paediatric problems in developing countries. The delayed recognition of the primary importance of oral rehydration in the management of acute watery diarrhoea; of the importance of Streptococcus pneumoniae and Haemophilus influenzae as the major causes of pneumonia in children in developing countries; and of the role of vitamin $\mathrm{A}$ in the management of severe measles are three important examples of this. Training based on such textbooks and without appropriate adaptation can do a major disservice to developing country physicians who graduate to work in outpatient or first referral level hospitals with limited drugs and equipment. They are unprepared to simplify what they have learned into an effective system and disappointed at not being able to deliver this care in their everyday practice. Postgraduate paediatric centres in industrialised countries that train more senior developing country doctors should ensure that their training is not solely based on their own national practice or that in standard textbooks of paediatrics but reflects the latest research findings and clinical experience from developing countries.

The success of this integrated approach will be highly dependent on the support and full participation of paediatricians. This is particularly important in in-service training of health workers, developing appropriate curricular mate- rials and teaching undergraduate doctors, clinical assistants, nurses and paramedical workers, and in carrying out essential clinical research on the management of the common childhood infections. Global guidelines will require considerable discussion and some adaptation before final adoption within each individual country. Developing country paediatricians are encouraged to participate in the promotion of this initiative within their own countries. They can play a central part in particular in the formulation of case management and drug policies, and in undergraduate and in-service training of doctors and other health workers. WHO are supporting the adaptation process in countries which are implementing this approach. ${ }^{26}$

Paediatricians from industrialised countries can give important support by recognising this initiative within national and international paediatric associations; and by taking part in the collaborative research to address some of the outstanding priority research questions. The initiative incorporates an evidence-based approach to guideline development; an integrated approach to training health professionals in the management of important childhood illnesses; priority in training given to essential skill acquisition (including communication skills); and attention given to key related issues such as management of essential drugs supplies and efforts to improve timely care seeking by families. The focus on these important issues is a particular strength of this global initiative which merits the support of all paediatricians. The case management approach that focuses on simple yet valid clinical signs and can be taught to health workers in peripheral health centres and health posts should contribute to a greatly increased access of families in developing countries to life saving care for the most common childhood illnesses. There may be considerable value in adapting this approach for use by primary care workers in developed countries.

HARRY CAMPBELL

Department of Public Health Medicine,

University of Edinburgh Medical School,

Teviot Place,

Edinburgh EH8 $9 A G$

School of Public Health,

University of California,

Berkeley, CA 94720, USA

(formerly of the Division of Child Health and Development, WHO)

SANDY GOVE

1 WHO Division of Diarrhoeal and Acute Respiratory Disease Control. Integrated management of the sick child. Bull World Health Organ 1995; 73:735grater

2 Garenne M, Ronsmans C, Campbell $\mathrm{H}$. The magnitude of mortality from acute respiratory infections in children under 5 years in developing countries. World Health Stat $Q$ 1992;45:180-91.

3 World Health Organisation. Technical bases for the WHO recommendations on the management of pneumonia in children at first level health facilities. WHO document WHO/ ARI / 91.20. Geneva: WHO, 1991.

4 Feachem RG. Preventing diarrhoea: what are the policy options? Health Policy and Planning 1989;1:109-17.

5 Kirkwood B, Gove S, Rogers, Lob Levyt J, Arthur P, Campbell H. Potential interventions for the prevention of childhood pneumonia in developing countries: a systematic review. Bull World Health Organ 1995;73:793-8.

6 World Bank. World development report. Investing in health. Oxford: Oxford University Press, 1993.

7 World Health Organisation. Division of diarrhoeal and acute respiratory disease control. Interim report 1994. WHO document WHO/COR/95.1. Geneva: control. Interim

8 Appropriate Health Resources and Technologies Action Group. Childhood pneumonia: strategies to meet the challenge. Proceedings of the first international consultation on the control of acute respiratory infections. London: AHRTAG, 1992 .

9 Brady JP, Awan FB, Wafula EM, Onyango FE. Recognition of illness in very young infants by inexperienced health workers. Ann Trop Paediatr 1993;13 401-7.

10 Lee LA, Dogore R, Redd SC, et al. Severe illness in African children with diarrhoea: implications for case management strategies. Bull World Health Organ 1995;73:779-85

11 Mulholland EK, Simoes EAF, Costales MOD, McGrath EJ, Manalac EM, Gove S. Standardized diagnosis of pneumonia in developing countries. Pediatr Infect Dis f 1991;11:77-81.

12 Sazawal S, Black RE. Meta-analysis of intervention trials on case management of pneumonia in community settings. Lancet 1992;340:52833. 
13 World Health Organisation Divisions of Diarrhoeal and Respiratory Disease Control (CDR) and Expanded Programme of Immunisation (EPI). Technical bases for the case management of measles. WHO document WHO/ CDR EPI. Geneva: WHO, 1995

14 Hussey GD, Klein M. A randomised, controlled trial of vitamin A in children with severe measles. N Engl F Med 1990;323:160-4.

15 Anonymous. Diarrhoeal Disease Control Programme. Diarrhoea case management survey. Wkly Epidemiol Rec 1990;65:21-4

16 World Health Organisation Division of Diarrhoeal and Acute Respiratory Disease Control. Integrated management of the sick child. A training course. Geneva: WHO, 1995

17 Cherian T, John TJ, Simoes E, Steinhoff MC, John M. Evaluation of simple clinical signs for the diagnosis of acute lower respiratory tract infection. Lancet 1989;ii:125-8.

18 Shann F, Hart K, Thomas D. Acute lower respiratory tract infections in children: Possible criteria for selection of patients for antibiotic therapy and children: Possible criteria for selection of patients for antibiotic the

19 Harari M, Shann F, Spooner V, Meisner S, Carney, De Campo J. Clinical Harari M, Shann F, Spooner V, Meisner S, Carney, De C
signs of pneumonia in children. Lancet 1991;338:928-30.

20 Campbell H, Byass P, Greenwood BM. Simple clinical signs for diagnosis of acute lower respiratory tract infections. Lancet 1988;ii:742-3.

21 Gove S, Tulloch J, Cattani J, Schapira A. Usefulness of clinical case definitions in the treatment of childhood malaria or pneumonia. Lancet 1993 341:304-5.

\section{Head lice in schoolchildren}

\author{
Ye ugle, creepin, blastit wonner, \\ Detested, shunned by saunt an' sinner, \\ How daur ye set your fit upon her, \\ Sae fine a lady. \\ Gae somewhere else and seek your dinner \\ On some poor body.
}

Robert Burns (1759-96, Scotland)

(Written after watching a louse move across a lady's bonnet during the kirk sermon.)

The sentiments expressed by Robert Burns-lice are disgusting, the well-off should be protected from them, and the poor deserve them-are common in Western society. They are enshrined in section 54 of the 1944 Butler Education Act, the most recent statute on the infestation of schoolchildren and still in force. The act implies that lice are caught by wilful negligence, the direct result of low standards of hygiene. It empowers a medical officer 'to ensure cleanliness' if a pupil at a state maintained school is found 'infested with vermin or in a foul condition', thus heightening the stigma attached to catching lice. In ministerial correspondence on child health, no subject features more frequently. ${ }^{1}$

\section{Biology}

The head louse, Pediculus capitis, feeds exclusively by sucking blood to which it has ready access on a clean head. It is host specific and an obligate parasite, spending its entire life on human heads. $P$ capitis lays its eggs singly, glued to the hairshaft where the warmth of the scalp will incubate them. The egg is tear shaped and $1 \mathrm{~mm}$ long. The louse emerges after seven to 10 days. Eggs and lice are well camouflaged, reflecting the colour of their surroundings. The empty eggshell (nit) turns white and becomes more obvious as the growing hair carries it away from the scalp. Infestation with head lice, pediculosis capitis, is commonly known as 'nits'. Although there can be hundreds of lice on a head, the average is only $10 .^{2-5}$ Contrary to expectations, lice may be present on a head for weeks or months without causing the characteristic itch.

The louse passes through three nymphal stages, growing by moulting its skin over 7 to 14 days. The adult louse is 3 mm long. The six legs end in claws used to cling to hairs. Lice cannot jump, but climb speedily from hair to hair. Transmission between hosts is by head to head contact when adult lice move to a new host at every opportunity.
22 World Health Organisation Programme for the Control of Acute Respiratory Infections. Acute respiratory infections in children: case management in small hospitals in developing countries. WHO document WHO/ARI/ 90.5. Geneva: WHO, 1990.

23 Coutsoudis A, Broughton M, Coovadia HM. Vitamin A supplementation reduces measles morbidity in young African children: a randomized, placebo-controlled, double-blind trial. Am f Clin Nutr 1991;54:890-5.

24 Redd SC, Kazembe PN, Luby SP, et al. Clinical algorithm for treatment of Plasmodium falciparum malaria in children. Lancet 1996;347:223-7.

25 Boele van Hensbroek M, Morris-Jones S, Meisner S, et al. Iron, but not folic acid, combined with effective antimalarial therapy promotes haematological recovery in African children after acute falciparum malaria. Trans $R$ Soc Trop Med Hyg 1995;89:672-6.

26 World Health Organisation Division of Child Health and Development. Management of childhood illness: adaptation guide working draft version 2 - fuly 1996. Geneva: WHO, 1996.

27 Sutrisna B, Reingold A, Kresno S, Harrison G, Utomo B. Care-seeking for fatal illnesses in young children in Indramayu, West Java, Indonesia. Lancet 1993;342:787-9.

28 Shann F, Duke T. Micronutrients, measles, malaria and mortality. Lancet 1995;346:s 16.

Nymphal stages tend to remain on the head where they hatch. ${ }^{2}$ When full grown, lice mate, whereupon the female begins to lay eggs, producing an average of 56 eggs after a single insemination, ${ }^{6}$ at the rate of about six per 24 hours.

Hatched lice move swiftly away from any disturbance in dry hair, but if thoroughly wetted, their mobility is much reduced. ${ }^{7}$ In 1985 it was shown that fine tooth combing of dripping hair after ordinary shampooing is a simple way to lift out lice. ${ }^{8}$ A fine toothed plastic comb is adequate and comfortable.

$P$ capitis is the evolutionary ancestor of Pediculus humanus, a second species which presumably appeared after humans began wearing clothes. ${ }^{9} P$ humanus, commonly known as the body or clothing louse, lays its eggs glued to cloth fibre and visits the skin to feed. With the development of $P$ humanus, the capacity of lice to spread typhus in infected droppings assumed significance, causing vast numbers of deaths down the centuries. The typhus pathogen, Rickettsia prowazeki, can remain infective for seven months, maintained in skin scale protein. It enters the body through skin abrasions and by inhalation. Those who cannot change their clothes, due to poverty or displacement, are vulnerable. European epidemics of typhus threatened during both world wars and it remains endemic in developing countries, and a peril to the refugees of armed conflict.

\section{Involvement of the school nurse}

Methods of mechanical control were advancing before the advent of DDT. In 1920 the Sackers, a family of barbers, developed a fine toothed metal comb capable of removing the eggs and shells. However, it requires a practised worker to perform the process effectively and fairly painlessly. Nurses in cleansing stations continued to use the tool even after the universal introduction of insecticidal shampoos and lotions, to distinguish treated from untreated heads.

School nurses have carried out head inspections in schools since 1890. Mellanby established in 1941 that these inspections usually miss all but the worst cases in school and showed that inspecting schoolchildren without also dealing with their contacts at home, is a self defeating policy. ${ }^{10}$ Nevertheless, the significance of this was apparently ignored by many school health services until the 1980s. Up to this time, the public and health professionals were convinced that these inspections were a useful diagnostic procedure. 